\title{
EVALUATION OF SATELLITE-DERIVED OBJECTIVE POTENTIAL INDEX FOR OCEANIC CLOUD SYSTEM DURING THE MEI-YU PERIOD
}

\author{
Chung-Chih Liu \\ Gin-Rong Liu \\ Chun-Chieh Chao \\ Weather Wing of China Air Force, Taipei, Taiwan. \\ Da-Gang Pan \\ Weather Wing of China Air Force, Taipei, Taiwan. \\ Ji-En Li \\ Weather Wing of China Air Force, Taipei, Taiwan.
}

Weather Wing of China Air Force, Taipei, Taiwan., vinliu2002@yahoo.com.tw

Space and Remote Sensing Research/Institute of Atmospheric Physics, National Central University, Taiwan.

Follow this and additional works at: https://jmstt.ntou.edu.tw/journal

Part of the Oceanography and Atmospheric Sciences and Meteorology Commons

\section{Recommended Citation}

Liu, Chung-Chih; Liu, Gin-Rong; Chao, Chun-Chieh; Pan, Da-Gang; and Li, Ji-En (2006) "EVALUATION OF SATELLITEDERIVED OBJECTIVE POTENTIAL INDEX FOR OCEANIC CLOUD SYSTEM DURING THE MEI-YU PERIOD," Journal of Marine Science and Technology. Vol. 14: Iss. 2, Article 1.

DOI: 10.51400/2709-6998.2059

Available at: https://jmstt.ntou.edu.tw/journal/vol14/iss2/1

This Research Article is brought to you for free and open access by Journal of Marine Science and Technology. It has been accepted for inclusion in Journal of Marine Science and Technology by an authorized editor of Journal of Marine Science and Technology. 
EVALUATION OF SATELLITE-DERIVED OBJECTIVE POTENTIAL INDEX FOR OCEANIC CLOUD SYSTEM DURING THE MEI-YU PERIOD

Acknowledgements

We would like to express our gratitude to the National Science Council in supporting the NSC92-

2111-M-072-001 Grant, NSC93-2111-M-344-001 Grant. and NSC 93-2625-Z-072-004 Grant. 


\title{
EVALUATION OF SATELLITE-DERIVED OBJECTIVE POTENTIAL INDEX FOR OCEANIC CLOUD SYSTEM DURING THE MEI-YU PERIOD
}

\author{
Chung-Chih Liu*, Gin-Rong Liu**, Chun-Chieh Chao*, Da-Gang Pan*, and Ji-En Li*
}

Key words: air-sea interaction, mesoscale convective system, objective potential index.

\begin{abstract}
Many mesoscale convective systems (MCSs) accompanied by heavy rainfall are frequently observed over the Taiwan Strait along the Mei-Yu front. An objective potential index of air-sea interaction was proposed by employing satellite data for pointing out areas where oceanic convective clouds may occur and develop into MCSs [11]. The aim of present research is to evaluate that index through the data of 2001 and 2002.

The results show that a greater objective potential index is correlated with a larger probability of colder infrared brightness temperature. In addition, the analysis of serial correlation for these two discrete parameters (objective potential index and GMS-5 IR1 brightness temperature) showed that the correlation coefficient is bigger in the South areas than in the North areas. Also, the leading time is larger in the Southareas. That may imply the air-sea interaction play a more important role and the oceanic convective clouds are more possible to start-up due to the effect of air-sea interaction in the South areas.

Since the synoptic scale environmental condition does also play an important role in oceanic convective systems' development, an improved objective potential index with the information of air conditional instability is under the investigation and it will be proposed in the near future.
\end{abstract}

\section{INTRODUCTION}

The role of air-sea interaction in oceanic convective systems has been a common topic since the late 1980s. Sanders and Gyakum [13] have pointed out that explosive winter cyclones occur most frequently near the regions with a strong sea surface temperature gradient. Bosart [1], Bosart and Lin [2] and Uccellini et al. [15] have all suggested that the large surface heat and moisture fluxes in the vicinity of the Gulf Stream along

Paper Submitted 02/03/05, Accepted 07/29/05. Author for Correspondence: Chung-Chih Liu.E-mail: vinliu2002@yahoo.com.tw.

*Weather Wing of China Air Force, Taipei, Taiwan.

**Space and Remote Sensing Research/Institute of Atmospheric Physics, National Central University, Taiwan. the east coast of the United States could have important effects on a storm's development. Kuo and Low-Nam [6] suggested that upward fluxes of water vapor and heat can pre-condition the storm environment for subsequent development. Kuo et al. [7] studied the effects of surface energy fluxes during the early development and rapid intensification stages of seven explosive cyclones in the western Atlantic Ocean by using the Pennsylvania State University/National Center for Atmospheric Research mesoscale model. They showed that the surface energy flux had a much stronger effect during the early stage of a storm's development than in the rapid cyclogenesis stage. Touchton [14] noted that the air-sea fluxes in the early stages of cyclone development might have helped to enhance its associated low level baroclinic zone and destabilize the lower atmosphere making the environment potentially unstable.

Many mesoscale convective systems (MCSs) accompanied by heavy rainfall are frequently observed over the Taiwan Strait and western Taiwan during May and June [3]. These systems often take a heavy toll on the local economy. Liu et al. [9] investigated the relationship between changes in the sea surface temperature and the MCSs' intensity over the oceans neighboring Taiwan during the Mei-Yu period. They found that a local increase in the sea surface temperature seemed to have a strong connection to the formation and intensification of MCSs. Liu and Liu [8] studied the relationship of the air-sea interaction with the MCS development, through several air-sea parameters derived from satellite data. The study also showed that the interactions between the atmosphere and the ocean seemed to be connected to the MCSs' genesis and development. In order to find information related to the development of MCSs, an algorithm for retrieval of near sea surface air temperature by using satellite was proposed [10, 12], and an objective potential index (OPI) was developed by employing satellite data [11]. They proved that OPI is a good reference in pointing out areas where convective clouds may occur and develop into MCSs. The purpose of this paper is to survey the 
applicability of OPI.

The paper is structured as follows. Data collection and processing are shown in Section 2. Afterwards, the methodology for surveying the applicability of OPI are described in Section 3. Some results and discussion are shown in Section 4. Finally, a summary is given in Section 5 .

\section{DATA}

The satellite data used in this research included The Special Sensor Microwave/Imager (SSM/I) and The Geostationary Meteorological Satellite (GMS-5) in May and June from 2001 to 2002. SSM/I are mounted on the Defense Meteorological Satellite Program (DMSP) sun-synchronous satellites, which orbit the earth at a height of $833 \mathrm{~km}$ and are oriented with an inclination of $98.8^{\circ}$ [5]. Generally, any area on the earth can be observed by these SSM/I sensors in less than 72 hours, except for two circular areas within a radius of $280 \mathrm{~km}$ from the South and North Poles. The SSM/I sensors provide four channels $(19 \mathrm{G} \mathrm{Hz}, 22 \mathrm{G} \mathrm{Hz}, 37 \mathrm{GHz}$ and $85 \mathrm{GHz}$ ), each having two polarization components (vertical and horizontal), except for the vertical polarization component at $22 \mathrm{G} \mathrm{Hz}$. GMS-5 satellite is a geostationary meteorological satellite that observes from a height of $36,000 \mathrm{~km}$ over the meridian at $140^{\circ} \mathrm{E}$. It provides hourly, plus 4 half-hourly observations in one visible, two infrared (IR1, 10.5 11.5 $\mu \mathrm{m}$ and IR2, $11.5 \sim 12.5 \mu \mathrm{m}$ ), and one water vapor (WV, 6.5 7.0 $\mu \mathrm{m}$ ) channel. To keep out the microwave data that are affected significantly by heavy rainfall drop particles, the SSM/I data are discarded if the following two relationships provide identical results [4].

$$
\begin{aligned}
& T_{b}(19 V)>165 K \\
& {\left[T_{b}(37 V)-T_{b}(37 H)\right]<37 K}
\end{aligned}
$$

where $T_{b}(19 \mathrm{~V}), T_{b}(37 \mathrm{~V})$ and $T_{b}(37 \mathrm{H})$ are the brightness temperatures observed on different channels. two channels $(19.35 \mathrm{GHz}$ and $37.0 \mathrm{GHz})$ which each has two polarization components (vertical and horizontal components; $\mathrm{V}$ and $\mathrm{H}$ )

The OPI was derived through SSM/I data. The $0.5^{\circ} \times 0.5^{\circ}$ longitude-latitude grid IR 1 infrared brightness temperature of the GMS-5 was used to match the resolution of SSM/I channels and to compare the derived OPI.

\section{METHODOLOGY}

Since the air-sea interactions may play an important role in the development of oceanic convective systems, Liu et al. [11] proposed the OPI to locate in advance the probable areas where energy may be transmitted from the ocean to the atmosphere, encouraging the development of MCSs. The complete procedure of OPI's derivation was illustrated in their paper. The brief interpret as following: At first, some SSM/I satellite-derived air-sea parameters (sea surface temperature, near sea surface air temperature, near sea surface air humidity, difference in temperature/humidity between air and sea, near sea surface wind, near sea surface latent/sensible heat flux) and their change rate per day were calculated for May and June 2001 to 2002. Liu et al. [11] have set the climatic maximum and minimum value of each SSM/I derived air-sea parameter and its daily variation as 1 and 0 , respectively. Therefore, each estimated air-sea parameter and its change rate per day were denoted as variables " $a$ " and " $b$ (where $b$ was computed with a daily backward difference)" in this research, respectively within this scale, by using an interpolation technique. The index for each air sea parameter could then be set to be $(a \times b) /(1 \times 1)$. Then, the OPI were derived by combining all the indices of air sea parameters as the following:

$$
O P I=\sum_{x=1}^{x=8} w_{x} \times I_{x}
$$

where $w$ is the normalized coefficient of the index for each air-sea parameter and $I$ is the value of each air-sea parameter index. The subscript $x$ indicates each air-sea parameter.

In order to understand correlation between oceanic convective systems and air-sea interaction, the correlation coefficient used to mean the coefficient of linear correlation between OPI and GMS-5 IR1 brightness temperature (IR1-TBB) was calculated in this research. Also the time lagged the correlation analysis of OPI and IR1-TBB was computed. The process of computing the time lagged correlation can be visualized by imagining two copies of a sequence of data pairs (OPI and IR1-TBB) being written, with one of the series shifted by one hour. The zero lagged time denotes the OPI and IR1-TBB being at the same time. While the positive lagged time denotes that the OPI appears earlier than IR1-TBB does. On the other hand, the negative lagged time denotes that the IR1-TBB brightness temperature appears earlier than OPI does. If the correlation coefficient of positive time lagged data pairs is larger than 0.5 (experience), it is reasonable to expect a higher probability for oceanic convective systems' appearance only thinking of air-sea interaction. That is OPI may serve as a good reference in pointing out areas where convective clouds may occur and develop into MCSs. 


\section{RESULTS AND DISCUSSIONS}

Many MCSs accompanied by heavy rainfall are frequently observed over the Taiwan Strait along the Mei-Yu front, then travel along with the front to Taiwan from the southeastern coast of Mainland China during May and June. Three small areas were set to be experimental areas in this research, covering from $25^{\circ} \mathrm{N}$ to $27^{\circ} \mathrm{N}$ and $120^{\circ} \mathrm{E}$ to $122^{\circ} \mathrm{E}$ (North Area), $22^{\circ} \mathrm{N}$ to $24^{\circ} \mathrm{N}$ and $118^{\circ} \mathrm{E}$ to $120^{\circ} \mathrm{E}$ (Middle Area), $19^{\circ} \mathrm{N}$ to $21^{\circ} \mathrm{N}$ and $115^{\circ} \mathrm{E}$ to $117^{\circ} \mathrm{E}$ (South Area), respectively. Figure 1 shows the locations of three experimental areas. The mean IR1-TBB and SSM/I derived OPI in the North Area during the period from May to June in 2001 and 2002 were shown in Figure 2. They show the fact that the majority of the events of IR1-TBB dropping down (smaller than $240 \mathrm{~K}$ ) accompany the OPI rising up (bigger than 0.5). The result seemed to imply strong correlation between air-sea interaction and oceanic convective systems. However, there are many other important conditions affecting the oceanic convective systems' development, such as a synoptic scale low level jet, a warm and moist air advection, and a convectively unstable layer. Therefore, the correlation coefficient

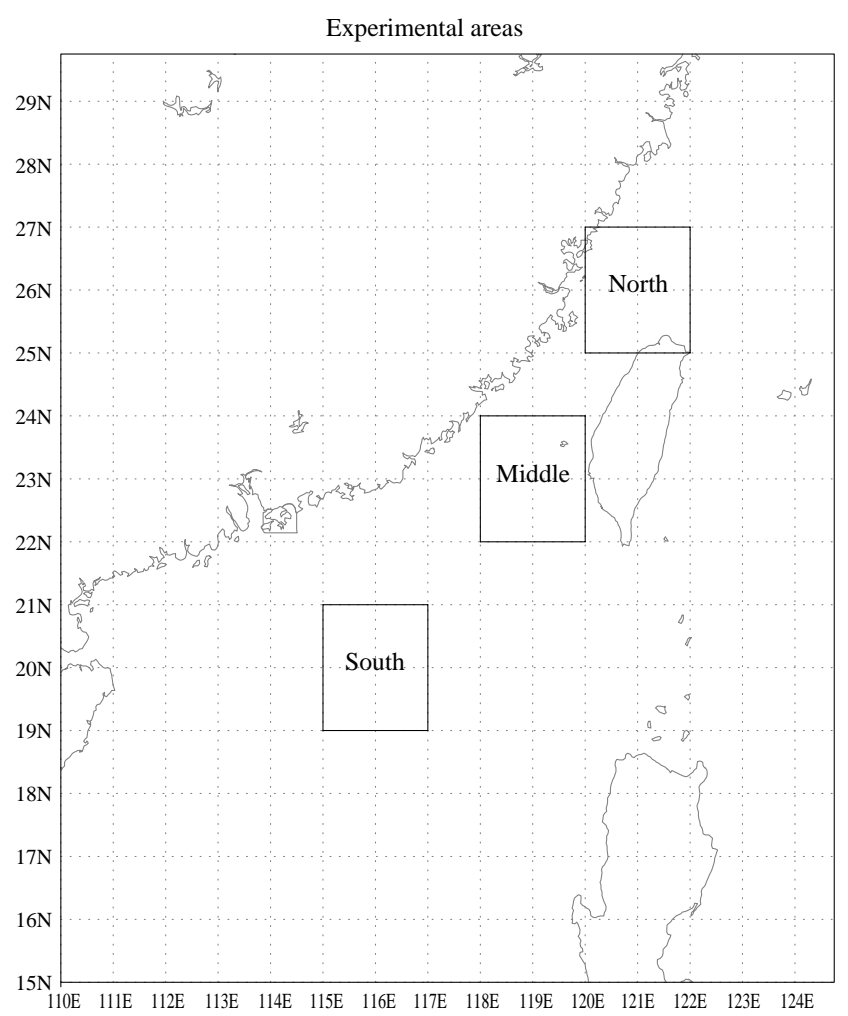

Fig. 1. The locations of three experimental areas covering from $25^{\circ} \mathrm{N}$ to $27^{\circ} \mathrm{N}$ and $120^{\circ} \mathrm{E}$ to $122^{\circ} \mathrm{E}$ (North Area), $22^{\circ} \mathrm{N}$ to $24^{\circ} \mathrm{N}$ and $118^{\circ} \mathrm{E}$ to $120^{\circ} \mathrm{E}$ (Middle Area), $19^{\circ} \mathrm{N}$ to $21^{\circ} \mathrm{N}$ and $115^{\circ} \mathrm{E}$ to $117^{\circ} \mathbf{E}$ (South Area). for all the data pairs in Figure 2 was only -0.51 (shown as Figure 3). Moreover, there exists a reasonable inference that the different magnitude of air-sea interaction could play a different role to start-up or maintain the growth of oceanic convective systems in a different synoptic scale condition. That is, a pronounced air-sea interaction (with a bigger OPI) may not induce oceanic convective systems in a very stable and dry synoptic scale environment.

To the contrary, a faint air-sea interaction (with a smaller OPI) may induce a convective system in a very unstable and moist synoptic scale environment. To examine the probable application of OPI in pointing out areas where convective clouds over ocean may occur and develop into convective systems, the mean probability distribution in North Area for various situations of IR1-TBB and OPI was shown in Figure 4. The smaller (bigger) IR1-TBB values show higher (lower) height of cloud top. The smaller (bigger) OPI values show weaker (stronger) air-sea interaction. Generally speaking, a bigger OPI value goes with a larger probability of small IR1-TBB. It shows a potential worthi-
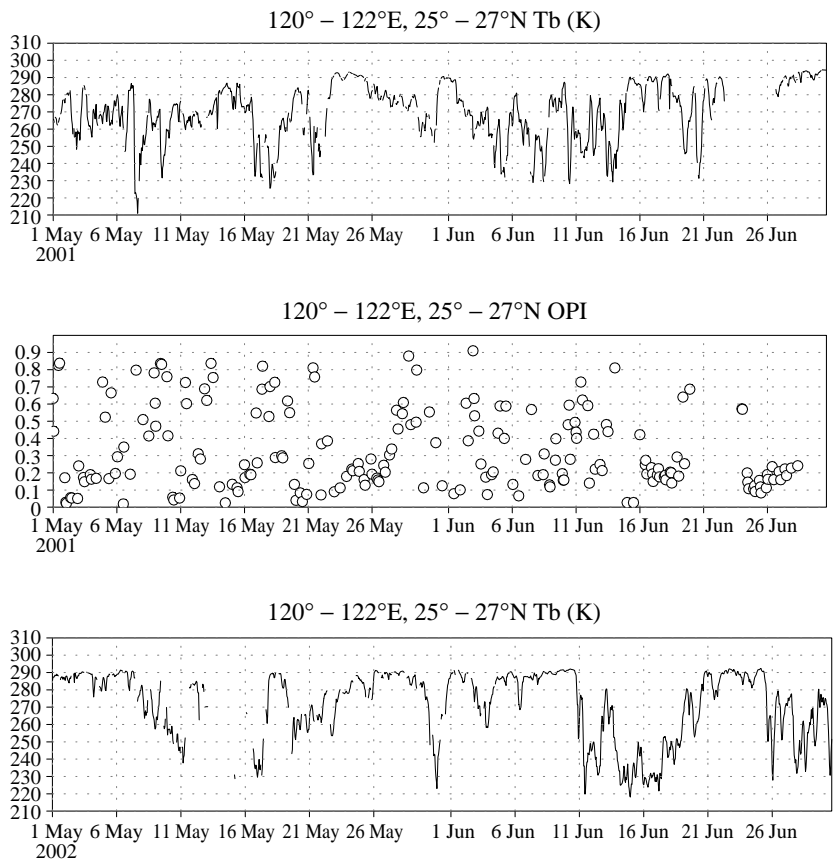

$120^{\circ}-122^{\circ} \mathrm{E}, 25^{\circ}-27^{\circ} \mathrm{N}$ OPI

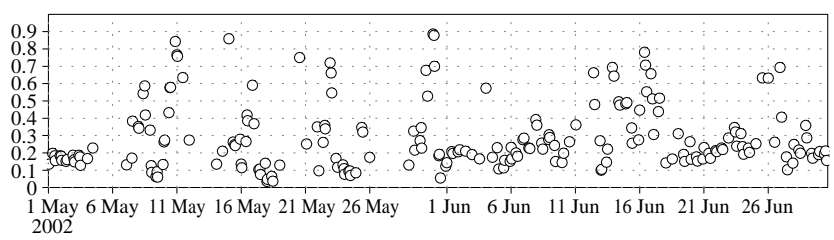

Fig. 2. The mean IR1-TBB and SSM/I derived OPI in the North Area during the period from May to June in 2001 and 2002. 
ness for monitoring the probable development of oceanic convective systems in the operational center.

Figures 5 show the mean IR1-TBB and SSM/I derived OPI in the Middle Area during the period from May to June in 2001 and 2002. The correlation coefficient for all the data pairs in Figure 5 was also only -0.51 (shown as Figure 6). Figure 7 show the mean probability distribution in the middle Area for various

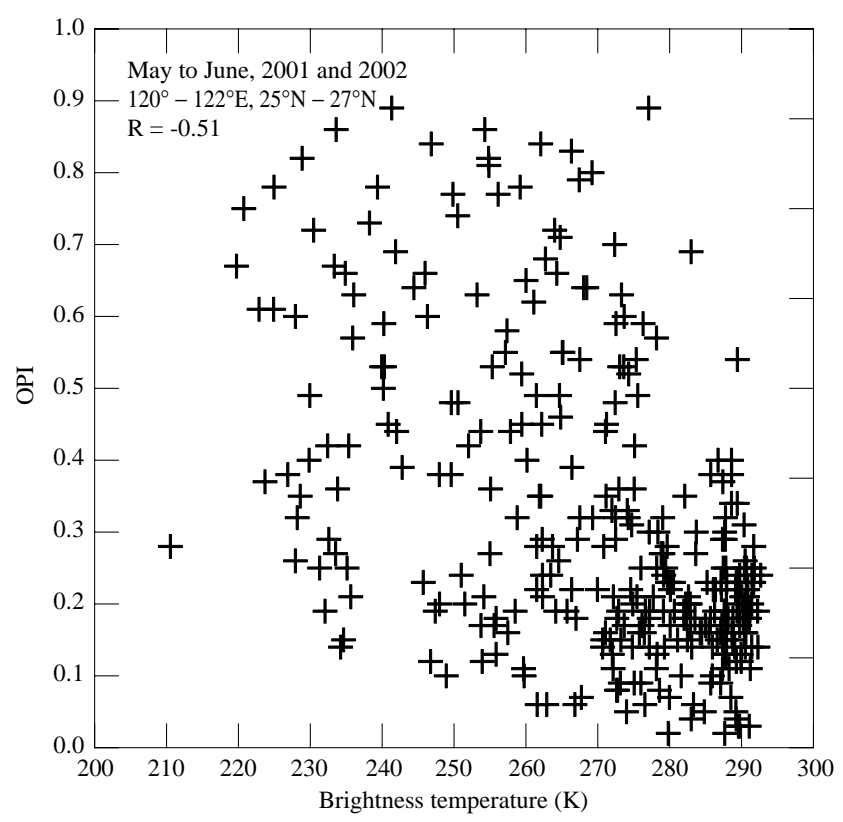

Fig. 3. The correlation coefficient for all the data pairs in Figure 2.

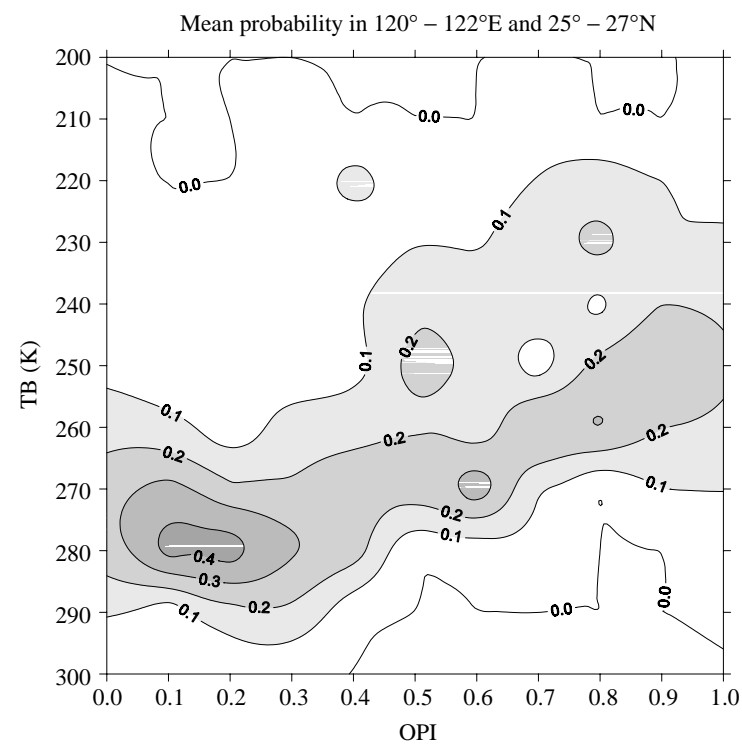

Fig. 4. The mean probability distribution in North Area for various situations of GMS-5 IR1 brightness temperature and satellite derived objective potential index during the period from May to June in 2001 and 2002.
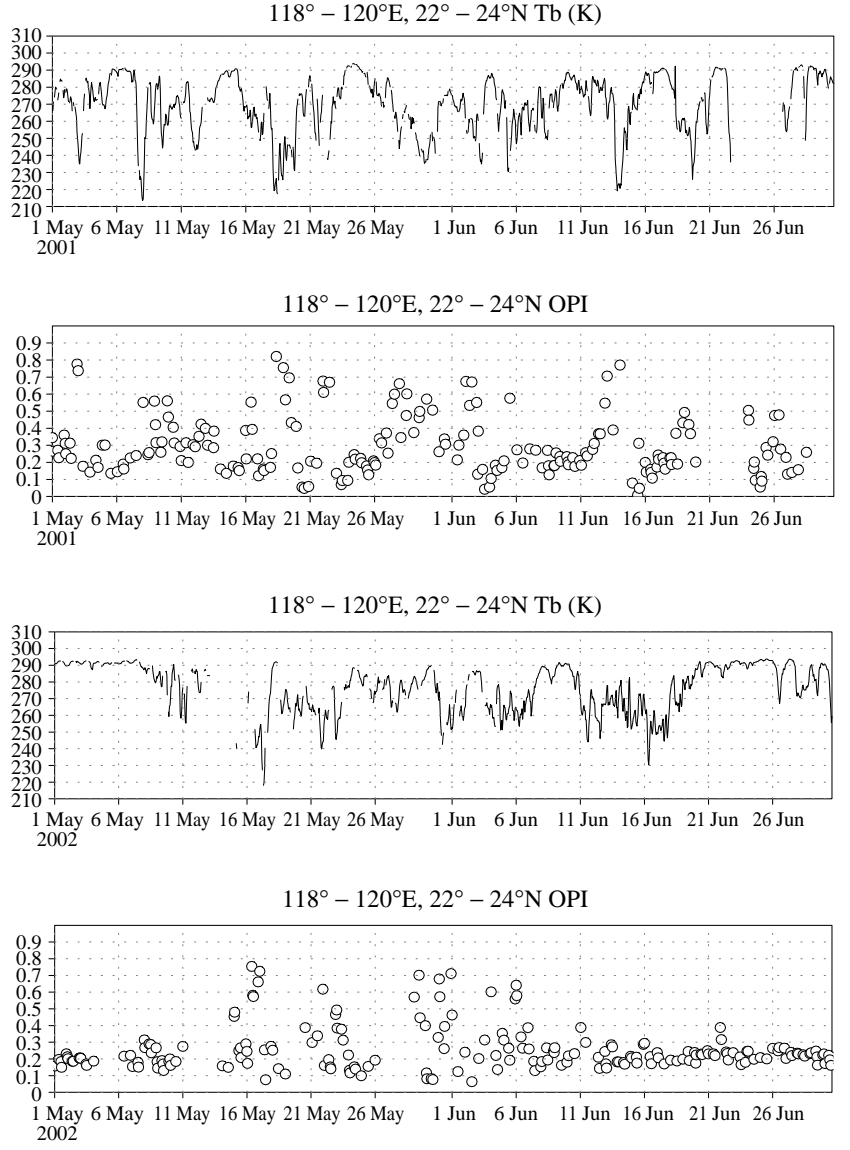

Fig. 5. The mean GMS-5 IR1 brightness temperature and satellite derived objective potential index in the Middle Area during the period from May to June in 2001 and 2002.

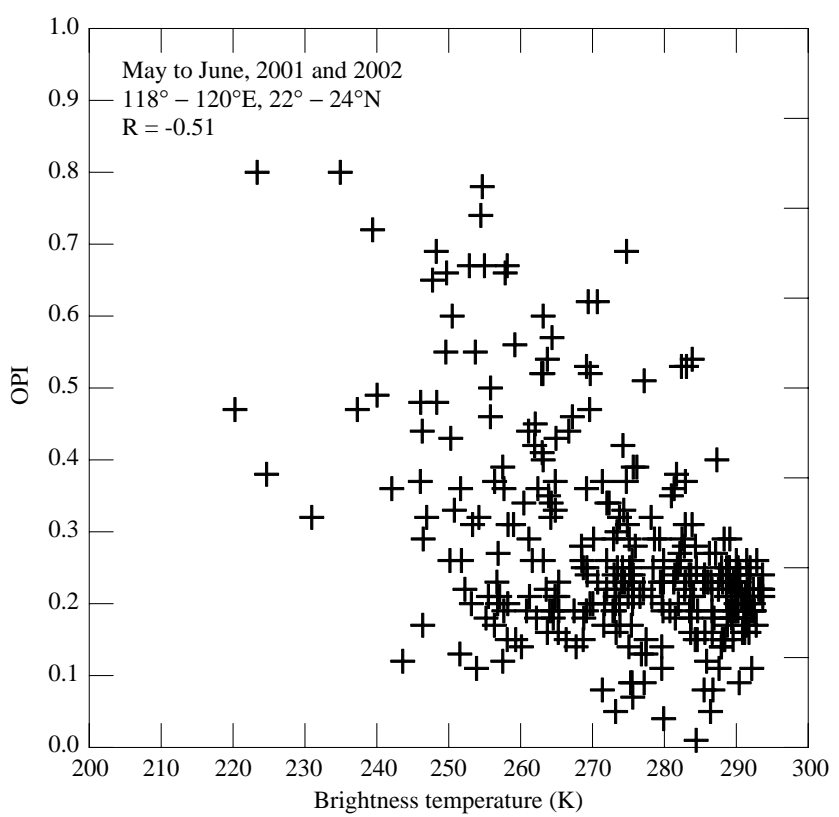

Fig. 6. The correlation coefficient for all the data pairs in Figure 5. 
situations of IR1-TBB brightness temperature and $O P I$. Figure 8 shows the IR1-TBB and SSM/I derived OPI in the South Area during the period from May to June in 2001 and 2002. The correlation coefficient for all the data pairs in Figure 8 was -0.53 (shown as Figure 9). Figure 10 shows the mean probability distribution in South Area for various situations of IR1-TBB and OPI. The results of analysis of the relationship between IRTBB and OPI in Middle and South areas also show the fact that a bigger OPI value goes with a larger probability of small IR1-TBB. However, it should be emphasized that aforemotioned synoptic scale situations also important for the oceanic convective system's development. For example, the air-sea interaction was expected to induce or maintain oceanic convective systems in the North areas during the periods from 11 to 16 , and 26 to 31 May 2001, while, there was not any telling convective system over these areas under such a weak and stable environment (not shown). In contrast, the air sea interaction was not expected to induce or maintain oceanic convective systems in the middle areas during the period from 9 to 20, June 2002, while, there did exist a telling convective systems over ocean (not shown). Of course it is more probable to see the development of oceanic convective systems in a suitable environment (both pronounced air sea interaction and strong synoptic conditions).

To figure out the serial correlation (also referred as lagged correlation) for two discrete parameters "OPI" and "IR1-TBB", two copies of a sequence of OPI and

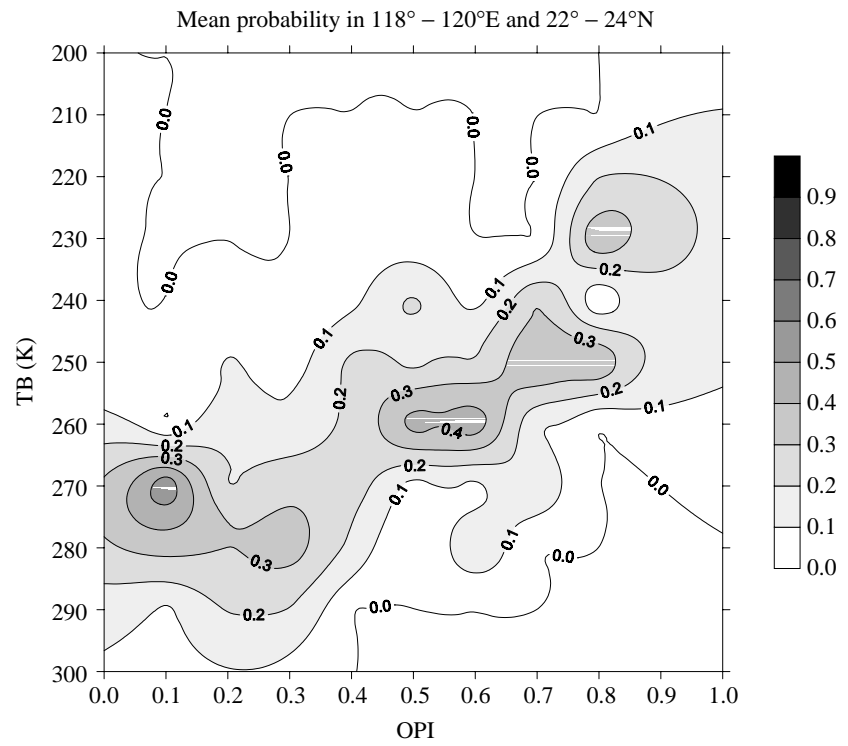

Fig. 7. The mean probability distribution in Middle Area for various situations of GMS-5 IR1 brightness temperature and satellite derived objective potential index during the period from May to June in 2001 and 2002.

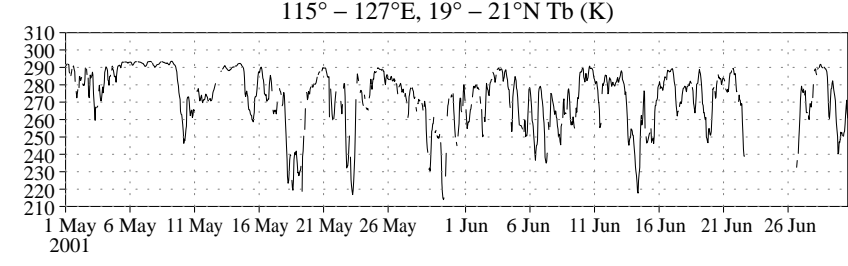

$115^{\circ}-127^{\circ} \mathrm{E}, 19^{\circ}-21^{\circ} \mathrm{N}$ OPI

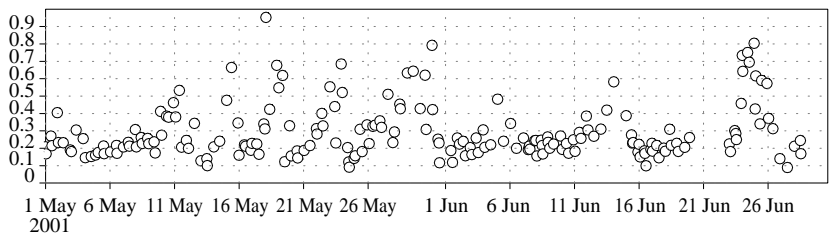

$115^{\circ}-117^{\circ} \mathrm{E}, 19^{\circ}-21^{\circ} \mathrm{N} \mathrm{Tb}(\mathrm{K})$

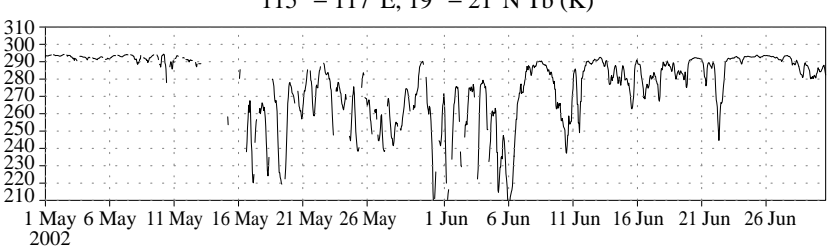

$115^{\circ}-117^{\circ} \mathrm{E}, 19^{\circ}-21^{\circ} \mathrm{N}$ OPI

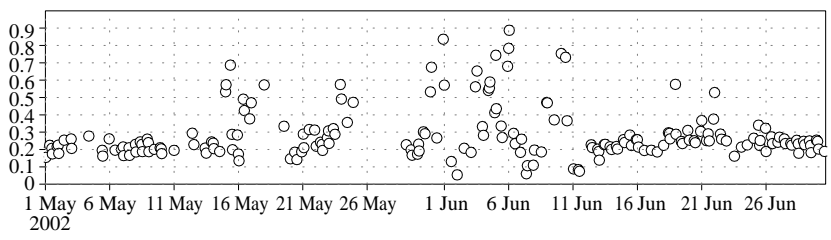

Fig. 8. The GMS-5 IR1 brightness temperature and satellite derived objective potential index in the South Area during the period from May to June in 2001 and 2002.

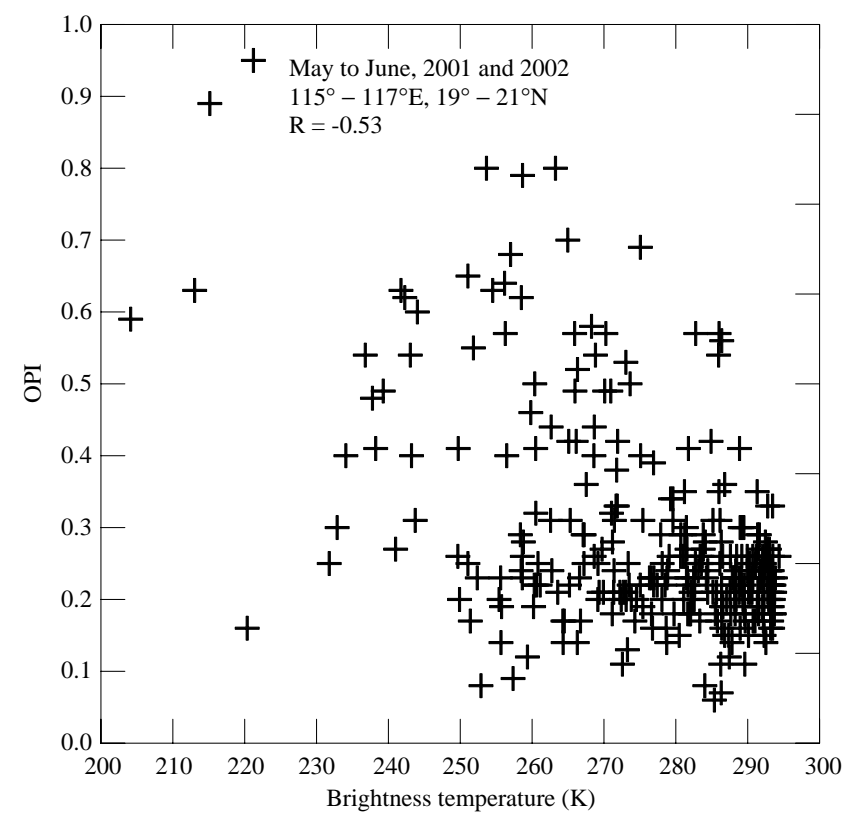

Fig. 9. The correlation coefficient for all the data pairs in Figure 8. 
IR1-TBB were written, and one of the series shifted by one hour. Then, the correlation coefficient was computed through the shifted data pairs. Figures 11, 12, and 13 show the variations of correlation coefficient of OPI and IR1-TBB for different shifted data pairs in the North Area, Middle Area, and South Area, respectively. The plus (negative) in the $x$-axis of Figures 11, 12, and 13 mean that OPI appears earlier (later) than IR1-TBB. The zero in the $x$-axis means no shift process, and the correlation coefficient was computed through the original data pairs with the same time. The bigger correlation coefficient (larger than 0.5) appears while leading time is four, eight, and twelve hour in North, Middle, and South areas, respectively. Therefore, the OPI may serves as a good reference (not necessary) in pointing out areas where oceanic convective clouds may occur. In addition, the correlation coefficient is bigger in the South areas than in the other two areas. And the leading time is also larger in the South areas than in the other two areas. That the thermodynamic conditions probably dominated the MCSs' early genesis and development over oceans may be the reason why the leading time of the South areas was longer than the other areas. That may also imply that air-sea interaction play a more important role in the South areas than in the other two areas. In other words, that shows a South areas' feature that the oceanic convective clouds are more possible to start-up over the oceans due to the effect of air-sea interaction. Of course, this research focuses only on the conditions at the air-sea boundary layer. It should be noted that the structure of the weather systems and the synoptic conditions also play an important role (sometimes more important than the boundary conditions). 


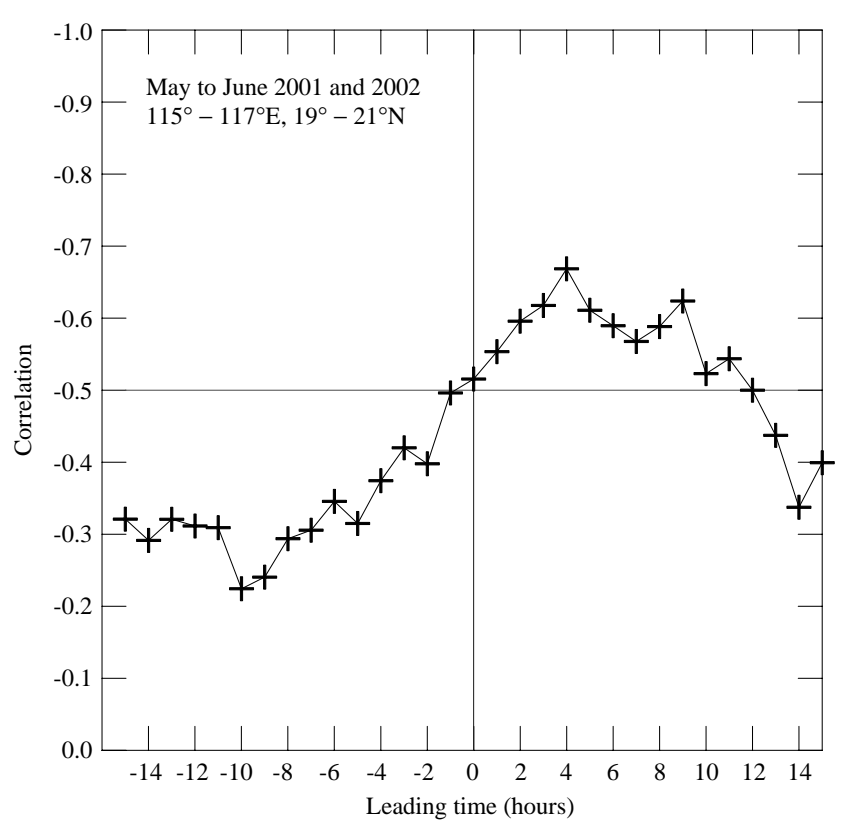

Fig. 13. The variations of correlation coefficient of GMS-5 IR1 brightness temperature and satellite derived objective potential index for different shifted data pairs in the South Area during the period from May to June in 2001 and 2002.

\section{CONCLUSION}

Under the hypothesis that air-sea interaction plays an importance role in MCSs' development, Liu et al. [11] proposed OPI by employing satellite data and demonstrate it be a good reference in pointing out areas where convective clouds may occur and develop into MCSs. The present research evaluates the applicability of OPI in operational weather center through the data of 2001 and 2002.

The results seems imply a strong correlation between air-sea interaction and oceanic convective systems due to the fact that the majority of the events of IR1 brightness temperature dropping down accompany the OPI rising up. The correlation coefficients between IR1-TBB and OPI are not big number due to the fact that some environmental conditions such as a synoptic scale low level jet, a warm and moist air advection, and a convectively unstable layer may also play an importance role. Therefore, a different strength of air-sea interaction could play a different role to start-up or maintain the growth of oceanic convective systems in a different synoptic scale condition. However, Generally speaking, a bigger OPI value goes with a larger probability of small IR1-TBB. It shows a potential worthiness for keep watching the probable development of oceanic convective systems through OPI in the operational weather center. In addition, the analysis of serial corre- lation for two discrete parameters "OPI" and "IR1TBB" showed the fact that the correlation coefficient is bigger in the South areas than in the other two areas. And the leading time is also larger in the South areas than in the other two areas. That may imply that air-sea interaction play a more important role in the South areas than in the other two areas. In other words, the oceanic convective clouds are more possible to start-up over the former areas due to the effect of air-sea interaction.

The aim of OPI's original setting out is to survey the air-sea interaction which was hypothesized to be important for the development of oceanic convective systems. However, there only exist the thermodynamic information in OPI. Actually, the synoptic scale environmental condition does also play an important role in their development absolutely. Therefore, the OPI should include the information both thermodynamic and dynamic condition. An improved OPI is under the investigative stage and it will be proposed in the near future.

\section{ACKNOWLEDGEMENTS}

We would like to express our gratitude to the National Science Council in supporting the NSC922111-M-072-001 Grant, NSC93-2111-M-344-001 Grant. and NSC 93-2625-Z-072-004 Grant.

\section{REFERENCES}

1. Bosart, L.F., "The Presidents' Day Snowstorm of 18-19 February 1979: A Subsynoptic-Scale Event," Monthly Weather Review, Vol. 109, pp. 1542-1566 (1981).

2. Bosart, L.F. and Lin, S.C., "A Diagnostic Analysis of the Presidents' Day Storm of February 1979," Monthly Weather Review, Vol. 112, pp. 2148-2177 (1984).

3. Chen, G.T.J. and Chou, H.C., "General Characteristics of Squall Lines Observed in TAMEX," Monthly Weather Review, Vol. 121, pp. 726-733 (1993).

4. Goodberlet, M.A. and Swift, C.T., "Improved Retrievals from the DMSP Wind Speed Algorithm Under Adverse Weather Condition," IEEE Transactions on Geoscience and Remote Sensing, Vol. 30, pp. 1076-1077 (1992).

5. Hollinger, J.P., Peirch, J.L., and Poe, G.A., "SSM/I Instrument Evaluation," IEEE Transactions on Geoscience and Remote Sensing, Vol. 28, pp. 781-790 (1990).

6. Kuo, Y.H. and Low-Nam, S., "Prediction of Nine Explosive Cyclones Over the Western Atlantic Ocean with a Regional Model," Monthly Weather Review, Vol. 118, pp. 3-25 (1990).

7. Kuo, Y.H., Reed, R.J., and Low-Nam, S., "Effects of Surface Energy Fluxes During the Early Development and Rapidly Intensification Stages of Seven Explosive Cyclones in the Western Atlantic," Monthly Weather Review, Vol. 119, pp. 457-476 (1991). 
8. Liu, C.C. and Liu, G.R., "A Preliminary Study on the Genesis of Meso Scale Convection System During Mei-Yu Period Using Satellite Data," Atmospheric Science, Vol. 28, pp. 1317-1341 (2000). (in Chinese)

9. Liu, G.R., Liu, C.C., and Liu, T.W., "Apply SSM/I Data to Estimate Sea Surface Temperature and Moisture," 1998 Western Pacific Geophysics Meeting (WPGM), Taipei, Taiwan (1998).

10. Liu, G.R., Liu, C.C., and Liu, T.H., "A Contrast and Comparison of Near-Sea Surface Air Temperature/Humidity from GMS and SSM/I Data with Improved Algorithm," IEEE Transactions on Geoscience and Remote Sensing, Vol. 39, pp. 2148-2157 (2001).

11. Liu, G.-R., Liu, C.-C., and Kuo, T.-H., "Satellite-Derived Objective Potential Index for MCS Development During the Mei-Yu Period," Journal of the Meteorological Society of Japan, Vol. 80, No. 3, pp. 503-517 (2002).
12. Liu, C.C., Liu, G.R., Chen, W.J., and Yang, H.Y., "Modified Bowen Ratio Method in Near-Sea Surface Air Temperature Estimation by Using Satellite Data," IEEE Transactions on Geoscience and Remote Sensing, Vol. 41, pp. 1025-1033 (2003).

13. Sanders, F. and Gyakum, J.R., "Synoptic-Dynamic Climatology of the Bomb," Monthly Weather Review, Vol. 108, pp. 1589-1606 (1980).

14. Touchton, M.E., "Examination of the 13 February 2001 Eastern Pacific Maritime Cyclogenesis," Master Thesis, Naval Postgraduate School, Monterey, CA (2002).

15. Uccellini, L.W., Petersen, R.A., Brill, K.F., Kocin, P.J., and Tuccillo, J.J., "Synergistic Interactions Between an Upper-Level Jet Streak and Diabatic Processes That Influence the Development of a Low-Level Jet and a Secondary Coastal Cyclone," Monthly Weather Review, Vol. 115, pp. 2227-2261 (1987). 